Article

\title{
Poly-Lactide/Exfoliated C30B Interactions and Influence on Thermo-Mechanical Properties Due to Artificial Weathering
}

\author{
Wendy Margarita Chávez-Montes, Guillermo González-Sánchez * \\ and Sergio Gabriel Flores-Gallardo
}

Centro de Investigación en Materiales Avanzados, S.C., Miguel de Cervantes No. 120,

Complejo Industrial Chihuahua, Chihuahua 31000, Mexico; wendy.chavez@cimav.edu.mx (W.M.C.-M.); sergio.flores@cimav.edu.mx (S.G.F.-G.)

* Correspondence: guillermo.gonzalez@cimav.edu.mx; Tel.: +52-614-439-4847

Academic Editor: Naozumi Teramoto

Received: 9 March 2016; Accepted: 14 April 2016; Published: 20 April 2016

\begin{abstract}
Thermal stability as well as enhanced mechanical properties of poly-lactide (PLA) can increase PLA applications for short-use products. The conjunction of adequate molecular weight $\left(M_{\mathrm{W}}\right)$ as well as satisfactory thermo-mechanical properties, together, can lead to the achievement of suitable properties. However, PLA is susceptible to thermal degradation and thus an undesired decay of $M_{\mathrm{W}}$ and a decrease of its mechanical properties during processing. To avoid this PLA degradation, nanofiller is incorporated as reinforcement to increase its thermo-mechanical properties. There are many papers focusing on filler effects on the thermal stability and mechanical properties of PLA/nanocomposites; however, these investigations lack an explanation of polymer/filler interactions. We propose interactions between PLA and Cloisite30B (C30B) as nanofiller. We also study the effects on the thermal and mechanical properties due to molecular weight decay after exposure to artificial weathering. PLA blank and nanocomposites were subjected to three time treatments $(0,176$, and $360 \mathrm{~h})$ of exposure to artificial weathering in order to achieve comparable materials with different $M_{\mathrm{W}}$. $M_{\mathrm{W}}$ was acquired by means of Gel Permeation Chromatography (GPC). Thermo-mechanical properties were investigated through Thermogravimetric Analysis (TGA), Differential Scanning Calorimetry (DSC), X-ray Diffraction (XRD), Dynamic Mechanical Thermal Analysis (DMTA) and Fourier Transform Infrared Spectroscopy (FTIR).
\end{abstract}

Keywords: PLA; nanocomposite; thermo-mechanical properties; biopolymer; artificial weathering

\section{Introduction}

Biodegradable polymers are currently materials of considerable interest due to their advantages, such as being environmental benign and having an origin of renewable resources. Among the bio-based and biodegradable polymers, poly-lactide (PLA) is one of the popular choices as it is now available largely at commercial scale [1]. PLA is a biodegradable thermoplastic that has restricted applications due to its brittleness and poor crystallization behavior. Blending PLA with clay at the nanorange can develop an increase in toughness and thermal properties [2-4]. A solution largely developed over the past years has consisted of the incorporation of nanosized reinforcements within the polymer matrix, yielding so-called nanocomposite materials [5-8]. Various types of nanofillers have been considered as reinforcing agents throughout PLA matrix in order to enhance its thermo-mechanical properties as well as to provide additional functionalities like barrier properties [7-9], improved biodegradation rate [10], biomedical applications [11] and fire-resistance attributes [6]. Clays used in nanocomposites are those denominated as "organoclays"; cationic complexes in which the surface metal cations of natural clays have been exchanged with an organic cation surfactant. The surfactant layer is organophilic, allowing 
the inorganic clays to be dispersed in organic polymers [12]. One of the clays that have been used in many studies for the preparation of polymer/clay nanocomposites is Cloisite30B (C30B), which is the result of the organic modification of a sodium montmorillonite. C30B consists of several hundred individual plate-like structures with dimensions of $1 \mu \mathrm{m} \times 1 \mu \mathrm{m} \times 1 \mathrm{~nm}$. These are held together by electrostatic forces. The uniform dispersion of C30B in PLA matrix is a general requirement for achieving improved mechanical and physical characteristics at the height of conventional plastics. Therefore, PLA is most likely to replace commodity plastics such as polyethylene (PE), polypropylene (PP), polystyrene (PS), and poly(ethylene terephthalate) (PET) [13-15]. However, to incorporate the C30B into a PLA matrix, it is often necessary to perform mixtures in molten state, which leads to a degradation of PLA and therefore molecular weight reduction. It has been observed that PLA is vulnerable to severe thermal degradation when it is processed above its melting temperature (especially above $180^{\circ} \mathrm{C}$ ). Thus, PLA processing undergoes heat transference and shear forces that results in a decrease of the molecular weight $\left(M_{\mathrm{W}}\right)$ of PLA caused by depolymerization reactions. In addition to the latter, natural weathering (a condition to which polymers are exposed along their useful life) can also result in a $M_{\mathrm{W}}$ decay due to humidity and photo-oxidation depolymerization reactions [15]; however, these conditions can be simulated in the laboratory. An undesired $M_{W}$ lowering of the final products results in poor mechanical performance and a reduction of thermal stability [13]. This unsatisfactory lack of heat stability and poor mechanical properties of PLA limits its applications [10], even when it was compounded to enhance them. According to Nieddu et al. [16], the combination of polymer and clays at the nanoscale, often results in remarkably improved mechanical and functional properties with respect to neat polymers or conventional composites, which leads to a higher Storage Modulus $\left(E^{\prime}\right)$. As the Modulus increases, the thermo-mechanical properties such as strength and heat resistance increase $[13,17]$. Although there have been several works studying the thermal and mechanical properties of PLA nanocompounded with clays, particularly Cloisite30B, the effect of molecular weight changes after artificial weathering exposure on the thermo-mechanical properties of nanocompounded PLA has not been sufficiently investigated. Since the molecular weight of polymers is one of the main factors affecting their thermal and mechanical properties, it is important to study the effect of molecular weight decay on the enhanced properties of nanocomposites, such as thermal resistance and elastic modulus. Additionally, interactions between PLA and nanoclay have not been explained. In this study, an organically modified layered montmorillonite-type C30B dispersed at nanorange throughout PLA matrix with different $M_{\mathrm{W}}$ due to artificial weathering was used in order to describe interactions between PLA and C30B, as well as the thermo-mechanical properties of PLA nanocomposites. In a previous work [18], we described the incorporation of $\mathrm{C} 30 \mathrm{~B}$ at the nanorange throughout PLA matrix, and so only the thermal and mechanical properties of these nanocomposites are presented in this paper.

\section{Materials and Methods}

PLA 2002D (semi-crystalline grade) was supplied by NatureWorks, Blair, NE, USA. PLA was stored in a dry, cool, and dark place before processing. Molecular weight distribution was determined by means of Gel Permeation Chromatography (GPC). An organomodified montmorillonite (MMT)-type Cloisite30B (C30B) was supplied by Southern Clay Products Inc. located in Gonzales, TX, USA and was used as filler. According to the manufacturer, the $\mathrm{C} 30 \mathrm{~B}$ was obtained by a modification of the natural MMT with a quaternary ammonium salt.

\subsection{Preparation of PLA Nanocomposite and Blank}

In a previous work [18], we studied the effect of artificial weathering on PLA filled with a nano-sized organomodified montmorillonite cloisite type C30B. After composite processing we found by means of X-ray diffraction (XRD) that the interplanar space on $\mathrm{d}_{001}$ increased due to the detachment of clay galleries. In addition, we studied the morphology of these composites by means of High Resolution-Transmission Electronic Microscopy (HR-TEM), and we could observe clay particles from 
single C30B platelet to eight stack platelets, both at nanorange. These results allowed us to conclude that clay particles' size diminished until it reaches nanoscale. These nanocomposites were the subject of this study as a complementary investigation dealing with the explanation of PLA/exfoliated $\mathrm{C} 30 \mathrm{~B}$ interactions and their influence on thermo-mechanical properties due to artificial weathering. However, the preparation of PLA blank and nanocomposites are again described in this paper as follows. Blends of semi-crystalline PLA were carried out with a 5\% load of C30B in order to obtain nanocomposites (named PLA/C30B) by a single-screw extruder Brabender Plasticorder DDRV752 (Brabender ${ }^{\circledR} \mathrm{GmbH} \&$ Co. KG, Kulturstr, Duisburg, Germany) with L/D ratio of 25:1, and a barrel of $19 \mathrm{~mm}$ in diameter. Mixtures were conducted with a temperature program of $150{ }^{\circ} \mathrm{C}$ in the feeding zone, and rose up to $180{ }^{\circ} \mathrm{C}$ in the die. The screw speed was set at $20 \mathrm{rpm}$. The mixtures were ground in a blender and introduced to a second extrusion stage under the same extruder conditions as previous in order to ensure a homogeneous material. Additionally, composites with dispersed filler at the nanoscale were obtained. The extrudate from the second stage was again ground. For the elaboration of flexion test probes, the ground extrudate from the second stage was placed into a Negri Bossi injection molding machine model V55-200 (New Castle, DE, USA) with mold temperature of $60^{\circ} \mathrm{C}$, and die temperature of $220^{\circ} \mathrm{C}$. PLA blank (PLA/B) was prepared with the same process as the nanocomposites but without the addition of C30B.

\subsection{Obtaining Materials with Different Molecular Weights}

In order to obtain materials with different molecular weights, the samples were degraded in an UV Artificial Weathering Tester (Q-Panel LabProducts Westlake, OH, USA) using a Fluorescent UVA-340 lamp with typical radiation of $0.77 \mathrm{~W} \cdot \mathrm{m}^{-2} \cdot \mathrm{nm}^{-1}$, and $260-400 \mathrm{~nm}$ wavelength with peak intensity in $340 \mathrm{~nm}$ at 0,176 , and $360 \mathrm{~h}$ of exposure according to cycle 1 of the ASTM D5272 test method as follows: firstly, $8 \mathrm{~h}$ of UV exposure period at the black panel temperature of $60 \pm 3^{\circ} \mathrm{C}$, followed by a condensation period of $4 \mathrm{~h}$ at the black panel temperature of $50 \pm 3^{\circ} \mathrm{C}$. This cycle was repeated as many times as needed until completion of exposure time.

\subsection{Characterization}

$M_{\mathrm{W}}$ and polydispersity index $\left(M_{n} / M_{\mathrm{W}}\right)$ of the original PLA (PLA neat), the blank (PLA/B), and the nanocomposite (PLA/C30B), was determined using an Agilent 1200 Infinity Series Gel Permeation Chromatograph (GPC) (Santa Clara, CA, USA). High Performance Liquid Chromatography (HPLC)-grade Tetrahydrofuran (THF) was used as eluent with an average flow rate of $1 \mathrm{~mL} \cdot \mathrm{min}^{-1}$ at $40{ }^{\circ} \mathrm{C}$. Polystyrene standards were used to calibrate the GPC. The samples were prepared at a concentration of $1 \mathrm{mg} \cdot \mathrm{mL}^{-1}$ in THF. Thermogravimetric Analysis (TGA) was performed on a TA Instruments calorimeter SDTQ600 (New Castle, DE, USA) using an airflow rate equal to $50 \mathrm{~mL} \cdot \mathrm{min}^{-1}$. Samples (ca. $15 \mathrm{mg}$ ) were placed in an alumina can. PLA/B and PLA/C30B were heated from ambient temperature to $550{ }^{\circ} \mathrm{C}$ at a heating rate of $10^{\circ} \mathrm{C} \cdot \mathrm{min}^{-1}$. Differential Scanning Calorimetry (DSC) tests were carried out using a TA Instruments Calorimeter DSC-Q 1000 (New Castle, DE, USA) under air atmosphere. Samples were heated at a scanning rate of $10^{\circ} \mathrm{C} \cdot \mathrm{min}^{-1}$ from 30 to $200{ }^{\circ} \mathrm{C}$. To investigate the thermal behavior of materials, Glass Transition Temperature $\left(T_{\mathrm{g}}\right)$, Melting Temperature $\left(T_{\mathrm{m}}\right)$, Melting Enthalpy $\left(\Delta H_{\mathrm{m}}\right)$, and Degree of Crystallinity $\left(X_{\mathrm{c}}\right)$, were determined from a second heating cycle. XRD measurements were performed on an X'Pert Pro of PANalytical X-ray diffractometer (Westborough, MA, USA) using Cu K $\alpha$. The data was collected over a range of scattering angles ( 2 theta) of $4^{\circ}-40^{\circ}$ and a scan speed of $0.4^{\circ} \cdot \mathrm{s}^{-1}$. Storage Modulus $\left(E^{\prime}\right)$ and Loss Tangent $(\tan \delta)$ were used as an indicator of the elastic modulus of the samples, and structural transformation was determined using a Dynamic Thermo-Mechanical Analyzer (DTMA) model RSAIII from TA Instruments (New Castle, $\mathrm{DE}, \mathrm{USA}$ ). For determination of the linear viscoelastic region (LVR), a strain sweep was carried out on each sample at $30^{\circ} \mathrm{C}$ at a frequency of $1 \mathrm{~Hz}$. Subsequently, a temperature sweep was performed from 30 to $90^{\circ} \mathrm{C}$ at a scanning rate of $3^{\circ} \mathrm{C} \cdot \mathrm{min}^{-1}$ under air atmosphere. The Attenuated Total Reflectance 
(ATR) by Fourier Transform Infrared (FTIR) spectra was recorded with a $4 \mathrm{~cm}^{-1}$ spectral resolution on a Perkin Elmer SpectrumGX spectrometer (Billerica, MA, USA) by signal-averaging 40 scans.

\section{Results}

\subsection{Molecular Weight}

Table 1 reports the $M_{\mathrm{W}}$ of PLA/B and PLA/C30B as a result of the exposure to artificial weathering; also, the $M_{\mathrm{W}}$ of neat PLA directly from the commercial pellets is reported.

Table 1. Molecular weight of samples.

\begin{tabular}{|c|c|c|c|c|}
\hline Sample & Exposure Time (h) & $M_{\mathrm{n}}\left(\mathrm{kg} \cdot \mathrm{mol}^{-1}\right)$ & $M_{\mathrm{W}}\left(\mathrm{kg} \cdot \mathrm{mol}^{-1}\right)$ & $M_{\mathrm{n}} / M_{\mathrm{W}}$ \\
\hline PLA neat & - & 135.9 & 329.0 & 2.42 \\
\hline \multirow{4}{*}{ PLA/B } & 0 & 49.0 & 125.0 & 2.55 \\
\hline & 176 & 33.1 & 74.3 & 2.25 \\
\hline & 360 & 16.4 & 33.3 & 2.03 \\
\hline & 0 & 43.5 & 99.0 & 2.27 \\
\hline \multirow{2}{*}{ PLA/C30B } & 176 & 31.9 & 69.7 & 2.18 \\
\hline & 360 & 11.3 & 22.8 & 1.72 \\
\hline
\end{tabular}

Number Average Molecular Weight $\left(M_{\mathrm{n}}\right)$ decay of PLA neat with respect to PLA/B and PLA/C30B at $0 \mathrm{~h}$ of exposure to artificial weathering was attributed to processing (extrusion and injection molding) of materials. Extrusion and injection molding of thermoplastics is a high-shear process that is performed in molten state. The effect of high shear rates and temperatures resulted in $M_{\mathrm{W}}$ decay in both PLA blank and nanocomposite. It could be observed that Weight Average Molecular Weight $\left(M_{\mathrm{W}}\right)$ and $M_{\mathrm{n}}$ in PLA/B and PLA/C30B showed a significant reduction as the exposure to artificial weathering was increased. This suggests a depolymerization of PLA chains, which occurs as a result of thermal scission, humidity, and photo-oxidation to which the samples were subjected. Original PLA had a $M_{\mathrm{n}}$ of $135.9 \mathrm{~kg} \cdot \mathrm{mol}^{-1}$. After processing, PLA/B and PLA/C30B $M_{\mathrm{n}}$ values were 49.0 and $43.5 \mathrm{~kg} \cdot \mathrm{mol}^{-1}$, respectively. When samples were exposed to artificial weathering, $M_{\mathrm{n}}$ decreased to values of $16.4 \mathrm{~kg} \cdot \mathrm{mol}^{-1}$ for PLA/B and $11.3 \mathrm{~kg} \cdot \mathrm{mol}^{-1}$ for PLA/C30B, both at maximum exposure time $(360 \mathrm{~h})$ to artificial weathering. These results clearly showed first the degradation during processing and second the photodegradation and hydrolysis of PLA during artificial weathering. It has been reported that artificial weathering occurs in the manner of chain scission [17,19]. Solarski et al. [20] examined the effects of ageing of neat PLA and PLA nanocomposite. They concluded that mechanical and thermal properties of PLA underwent strong modifications due artificial weathering. They also observed faster degradation in PLA nanocomposites.

\subsection{Thermo-Mechanical Properties}

Filler/polymer interactions were described by a change in the thermal and mechanical properties of PLA/C30B compared with PLA/B. This change of thermo-mechanical properties was related to a reduction of the $M_{\mathrm{W}}$ of the studied materials. The effect of $M_{\mathrm{W}}$ on the thermo-mechanical properties of PLA blank and nanocomposite was studied by means of TGA, DSC, and DTMA.

\subsubsection{Thermogravimetric Analysis (TGA)}

Thermo-gravimetric analysis in the literature [12] has shown that the organic component of organoclays begins to break down at temperatures $c a .180^{\circ} \mathrm{C}$ under non-oxidative environments, and significant degradation occurs just above this temperature. These degradation temperatures may be exceeded during melt processing of PLA. Therefore, it is of prime importance to study the thermal 
stability of the organic modifier and its implications for nanocomposite processing and properties. Figure 1 shows the thermogravimetric analysis of C30B. In order to observe the weight loss of the organomodifier during nanocomposite processing, a thermo-gravimetric (TG) curve from 30 to $800{ }^{\circ} \mathrm{C}$ at a heating rate of $10^{\circ} \mathrm{C} \cdot \mathrm{min}^{-1}$ was performed, with two thermal treatments of $\mathrm{C} 30 \mathrm{~B}$ carried out at $180{ }^{\circ} \mathrm{C}$ for $10 \mathrm{~min}$ followed by another isotherm at $220^{\circ} \mathrm{C}$ for $2 \mathrm{~min}$, which correspond to the extrusion process followed by injection molding. The results showed that the weight loss of organomodifier was negligible $(2.52 \%)$. We concluded that the content of organomodifier of C30B (amounting to about one third of the total mass) remains available to allow interactions with PLA. In addition, C30B alone was subjected to the same three exposure times of artificial weathering $(0,176$, and $360 \mathrm{~h})$ of blank and nanocomposites to observe a possible degradation of organomodifier due artificial weathering. However, from TGA measurements, the remaining organomodifier content in all the samples at the three exposure times to artificial weathering was $c a$. 30\%. In addition, the onset of degradation of C30B was shown to occur at $c a .180^{\circ} \mathrm{C}$ and the loss of decomposition products took place in two steps at $180{ }^{\circ} \mathrm{C}$ and ca. $400{ }^{\circ} \mathrm{C}$. According to Filippi S. et al. [21], the first event of weight loss is due to degradation of the unconfined organomodifier that did not take part in the cation exchange reaction during synthesis. The presence of unreacted organomodifier on the surface of the organoclay particles was ascribed to improper washing during manufacture.

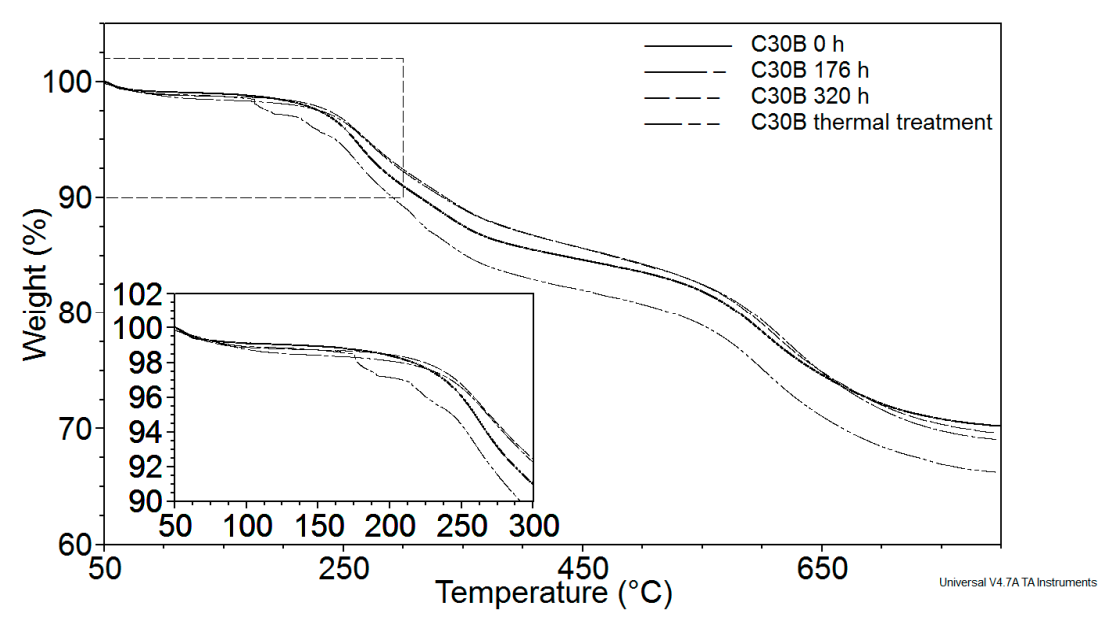

Figure 1. Thermogravimetric analysis of $\mathrm{C} 30 \mathrm{~B}$ exposed to both thermal treatment and artificial weathering.

The weight loss curve shows the loss of mass at a constant heating rate of PLA/B $\left(M_{\mathrm{n}}\right.$ in $\mathrm{kg} \cdot \mathrm{mol}^{-1}$ of $\mathrm{A}=49.04, \mathrm{~B}=33.06, \mathrm{C}=16.40)$ in Figure 2a and PLA/C30B $\left(M_{n}\right.$ in $\mathrm{kg} \cdot \mathrm{mol}^{-1}$ of $\mathrm{D}=43.49, \mathrm{E}=31.90$, $\mathrm{F}=11.32$ ) in Figure $2 \mathrm{~b}$. As can be seen from the plot, the decomposition process of PLA begins at about $300{ }^{\circ} \mathrm{C}$ and proceeds rapidly as the temperature increases up to $400{ }^{\circ} \mathrm{C}$ for all samples. It was also observed that the decomposition of PLA underwent a shift of sigmoidal curve shape to lower temperatures when $M_{\mathrm{n}}$ decreased, in both PLA/B and PLA/C30B. This can be attributed to the size of chains. Smaller PLA chains have fewer bonds to break down than larger PLA chains; therefore, it requires less energy to decompose PLA into $\mathrm{CO}_{2}$ and water [13]. PLA with the lowest $M_{\mathrm{n}}$ (Figure $2 \mathrm{aC}, \mathrm{bF}$ ) showed more pronounced weight loss decay on temperatures between $\mathrm{ca}$. 280 to $350{ }^{\circ} \mathrm{C}$. Degradation of PLA chains starts when the covalent bonds between atoms begin to split apart. Therefore, $M_{n}$ decreased due to breakage of PLA chains until it transformed to $\mathrm{CO}_{2}$ and water. From Figure $2 \mathrm{~b}$, a residue at $c a$. 95\% of weight loss can be seen, which corresponds to the quantity ( $5 \%$ weight residue) of C30B used as filler to obtain nanocomposites. Furthermore, even though a sigmoidal TG curve shape shift was observed, the temperature at which all samples were completely degraded was the same in both PLA/B and PLA/C30B, even when they had different $M_{n}$. 


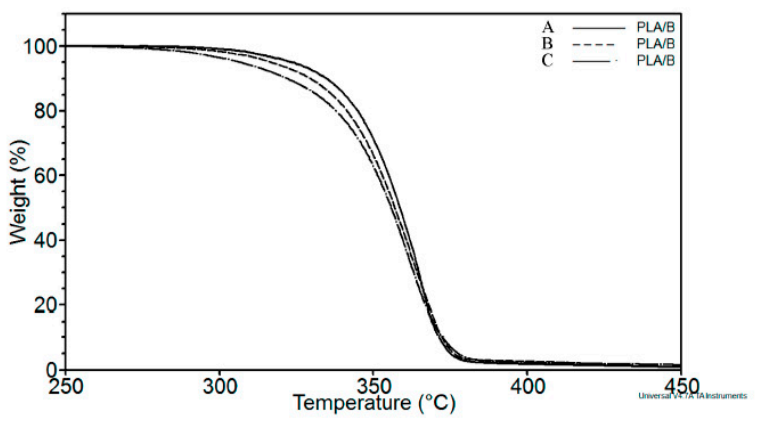

(a)

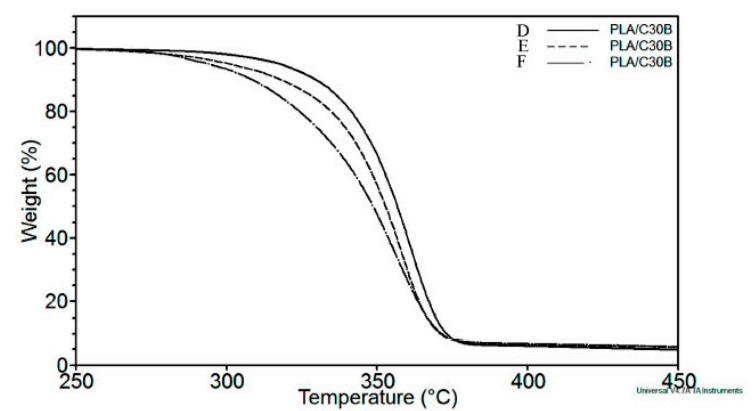

(b)

Figure 2. Thermogravimetric analysis (TGA) of (a) PLA/B $\left(M_{n}\right.$ in $\mathrm{kg} \cdot \mathrm{mol}^{-1}$ of $\mathrm{A}=49.0, \mathrm{~B}=33.1$, and $\mathrm{C}=16.4)$ and; (b) PLA/C30B $\left(M_{\mathrm{n}}\right.$ in $\mathrm{kg} \cdot \mathrm{mol}^{-1}$ of $\mathrm{D}=43.5, \mathrm{E}=31.9$ and $\left.\mathrm{F}=11.3\right)$.

Data of the decomposition temperatures from $T_{10 \%}$ to $T_{90 \%}$ of weight loss are shown in Table 2 . $T_{10 \%}$ of PLA/C30B shifted down ca. $6^{\circ} \mathrm{C}$ in comparison to PLA/B, both with the highest $M_{\mathrm{n}}$ (without exposure to artificial weathering). This means that thermal degradation of PLA nanocomposites starts earlier than those obtained with the same processing but without the addition of $\mathrm{C} 30 \mathrm{~B}$. Similarily, PLA/C30B with the lowest $M_{\mathrm{n}}$ showed a decrease of $T_{10 \%}$ from about $21^{\circ} \mathrm{C}$ in comparison to PLA/C30B with the highest $M_{\mathrm{n}}$. This indicates that chain breakage in PLA nanocomposites with shorter chains starts earlier than nanocomposites with bigger chains. Additionally, it was observed that $T_{90 \%}$ of PLA/B showed a small difference of $c a .1{ }^{\circ} \mathrm{C}$ in samples with the highest, medium, and lowest $M_{n}$. This behavior resembles $T_{90 \%}$ of PLA/C30B with a variance of $c a .3^{\circ} \mathrm{C}$ in different $M_{\mathrm{n}}$. Thermal degradation resistance of PLA matrix was not improved by the presence of C30B in comparison with PLA/B. This effect was also reported by Pandey et al. [22] in their research, where they showed that PLA degradation took place even in the presence of an antioxidant. However, the contrary effect was reported by Fukushima et al. [6]. They found a significant stabilizing effect blending PLA with C30B, showing an increase of $T_{5 \%}$ and $T_{\max }$ in comparison to its blank. Although there are several works regarding PLA nanocomposite thermal degradation, there is a lack of congruence in the results found on the thermal behavior of PLA nanocomposites. In this study, earlier degradation on nanocomposites occurred in comparison with blank PLA, which can be attributed to the presence of C30B, which decreases the activation energy of depolymerization reactions in thermal degradation.

Table 2. Decomposition temperature at $10 \%-90 \%$ of weight loss.

\begin{tabular}{|c|c|c|c|c|c|c|}
\hline \multicolumn{4}{|c|}{ PLA/B (Temperature ${ }^{\circ} \mathrm{C}$ ) } & \multicolumn{3}{|c|}{ PLA/C30B (Temperature ${ }^{\circ} \mathrm{C}$ ) } \\
\hline Weight loss (\%) & $\begin{array}{c}M_{\mathrm{n}} \\
49.04 \mathrm{~kg} \cdot \mathrm{mol}^{-1}\end{array}$ & $\begin{array}{c}M_{\mathrm{n}} \\
33.06 \mathrm{~kg} \cdot \mathrm{mol}^{-1}\end{array}$ & $\begin{array}{c}M_{\mathrm{n}} \\
16.40 \mathrm{~kg} \cdot \mathrm{mol}^{-1}\end{array}$ & $\begin{array}{c}M_{\mathrm{n}} \\
43.49 \mathrm{~kg} \cdot \mathrm{mol}^{-1}\end{array}$ & $\begin{array}{c}M_{\mathrm{n}} \\
31.90 \mathrm{~kg} \cdot \mathrm{mol}^{-1}\end{array}$ & $\begin{array}{c}M_{\mathrm{n}} \\
11.32 \mathrm{~kg} \cdot \mathrm{mol}^{-1}\end{array}$ \\
\hline 10 & 334.81 & 329.57 & 318.05 & 328.77 & 313.80 & 307.60 \\
\hline 20 & 344.94 & 341.42 & 336.15 & 340.99 & 332.84 & 323.65 \\
\hline 30 & 350.69 & 348.06 & 344.94 & 347.77 & 341.89 & 334.43 \\
\hline 40 & 355.03 & 352.93 & 350.65 & 352.6 & 347.68 & 342.34 \\
\hline 50 & 358.70 & 357.01 & 355.18 & 356.55 & 352.16 & 348.42 \\
\hline 60 & 361.95 & 360.68 & 359.01 & 360.02 & 355.99 & 353.50 \\
\hline 70 & 364.81 & 364.22 & 362.51 & 363.31 & 359.45 & 358.23 \\
\hline 80 & 367.45 & 367.93 & 366.20 & 366.96 & 363.13 & 363.28 \\
\hline 90 & 371.42 & 372.38 & 371.42 & 372.72 & 369.33 & 370.93 \\
\hline
\end{tabular}

\subsubsection{Differential Scanning Calorimetry (DSC)}

The glass transition $\left(T_{\mathrm{g}}\right)$, cold crystallization $\left(T_{\mathrm{c}}\right)$, and melting $\left(T_{\mathrm{m}}\right)$ temperatures of PLA/B $\left(M_{\mathrm{n}}\right.$ in $\mathrm{kg} \cdot \mathrm{mol}^{-1}$ of $\left.\mathrm{A}=49.04, \mathrm{~B}=33.06, \mathrm{C}=16.40\right)$ and PLA $/ \mathrm{C} 30 \mathrm{~B}\left(M_{\mathrm{n}}\right.$ in $\mathrm{kg} \cdot \mathrm{mol}^{-1}$ of $\mathrm{D}=43.49, \mathrm{E}=31.90$, $\mathrm{F}=11.32$ ) recorded after cooling and on a second heating cycle by DSC are shown in Figure 3. 


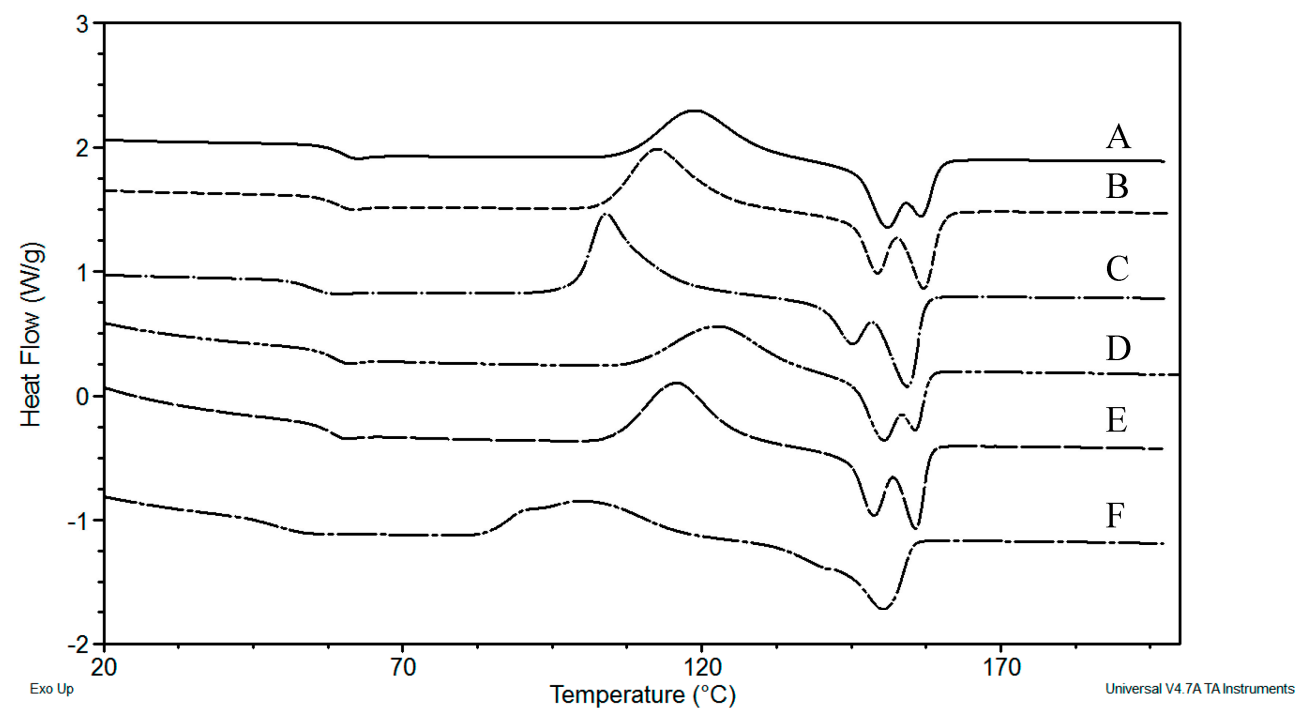

Figure 3. Differential Scanning Calorimetry (DSC) curves of PLA/B $\left(M_{\mathrm{n}}\right.$ in $\mathrm{kg} \cdot \mathrm{mol}^{-1}$ of $\mathrm{A}=49.0$, $\mathrm{B}=33.1$, and $\mathrm{C}=16.4)$ and $\mathrm{PLA} / \mathrm{C} 30 \mathrm{~B}\left(M_{\mathrm{n}}\right.$ in $\mathrm{kg} \cdot \mathrm{mol}^{-1}$ of $\mathrm{D}=43.5, \mathrm{E}=31.9$ and $\left.\mathrm{F}=11.3\right)$.

Table 3 reports the thermal events, crystallization enthalpy $\left(H_{\mathrm{c}}\right)$, and crystallinity $\left(X_{\mathrm{c}}\right)$ of PLA/B and PLA/C30B with different $M_{\mathrm{n}}$.

Table 3. Thermal events and crystallinity of PLA blank and nanocomposites.

\begin{tabular}{|c|c|c|c|c|c|c|c|c|c|c|c|}
\hline \multicolumn{6}{|c|}{ PLA/B } & \multicolumn{6}{|c|}{ PLA/C30B } \\
\hline $\begin{array}{c}M_{\mathrm{n}} \\
\left(\mathrm{kg} \cdot \mathrm{mol}^{-1}\right)\end{array}$ & $\begin{array}{c}T_{\mathrm{g}} \\
\left({ }^{\circ} \mathrm{C}\right)\end{array}$ & $\begin{array}{c}T_{\mathrm{c}} \\
\left({ }^{\circ} \mathrm{C}\right)\end{array}$ & $\begin{array}{c}T_{\mathrm{m}} \\
\left({ }^{\circ} \mathrm{C}\right)\end{array}$ & $\begin{array}{c}\Delta H_{\mathrm{c}} \\
\left(\mathrm{J} \cdot \mathrm{g}^{-1}\right)\end{array}$ & $\begin{array}{l}X_{c} \\
(\%)\end{array}$ & $\begin{array}{c}M_{\mathrm{n}} \\
\left(\mathrm{kg} \cdot \mathrm{mol}^{-1}\right)\end{array}$ & $\begin{array}{c}T_{\mathrm{g}} \\
\left({ }^{\circ} \mathrm{C}\right)\end{array}$ & $\begin{array}{c}T_{\mathrm{c}} \\
\left({ }^{\circ} \mathrm{C}\right)\end{array}$ & $\begin{array}{c}T_{\mathrm{m}} \\
\left({ }^{\circ} \mathrm{C}\right)\end{array}$ & $\begin{array}{c}\Delta H_{\mathrm{c}} \\
\left(\mathrm{J} \cdot \mathrm{g}^{-1}\right)\end{array}$ & $\begin{array}{c}X_{\mathrm{c}} \\
(\%)\end{array}$ \\
\hline 49.0 & 59.86 & 119.13 & 156.83 & 35.96 & 22.75 & 43.5 & 58.27 & 122.77 & 155.85 & 33.14 & 18.92 \\
\hline 33.1 & 59.22 & 112.66 & 157.32 & 37.52 & 23.93 & 31.9 & 58.07 & 115.72 & 155.86 & 38.24 & 23.23 \\
\hline 16.4 & 55.08 & 104.02 & 154.56 & 38.16 & 27.75 & 11.3 & 48.49 & 100.12 & 150.46 & 39.13 & 27.01 \\
\hline
\end{tabular}

It can be observed that $T_{\mathrm{g}}$ on both PLA/B and PLA/C30B decreases as $M_{\mathrm{n}}$ decreases. According to Rasselet et al. [23], a $T_{\mathrm{g}}$ decrease can, without any doubt, be attributed to chain scission occurring during oxidation. Indeed, in the case of linear polymers such as PLA, $T_{\mathrm{g}}$ and $M_{\mathrm{n}}$ are directly related by the Fox-Flory relationship [24]. When the PLA temperature is below its $T_{\mathrm{g}}$, large-scale molecular motion is not possible because the material is essentially frozen; after this temperature (on heating), the glassy state changes into rubbery on melt state. $T_{\mathrm{g}}$ decreased from 59.86 to $55.08^{\circ} \mathrm{C}$ in PLA/B, and from 58.27 to $48.49^{\circ} \mathrm{C}$ in PLA/C30B as $\mathrm{M}_{\mathrm{n}}$ diminished. Similar to $T_{\mathrm{g}}, T_{\mathrm{m}}$ decreased $c a .2{ }^{\circ} \mathrm{C}$ in PLA/B and $c a .5{ }^{\circ} \mathrm{C}$ in PLA/C30B in the lowest $M_{n}$. However, the reduction of $M_{n}$ did not noticeably affect the crystallization of PLA blank because longer chains require more kinetic energy to crystallize. An increase of $X_{\mathrm{c}}(5 \%)$ was evidenced in the lowest $M_{\mathrm{n}}$. Additionally, the addition of C30B in the PLA matrix led to a major increase of $X_{\mathrm{c}}(8 \%)$ in nanocomposites with the lowest $M_{\mathrm{n}}$ in comparison with nanocomposites with the highest $M_{\mathrm{n}}$. This may be due to the presence of $\mathrm{C} 30 \mathrm{~B}$ and short chains, which, together, can originate segmental motions at the PLA/C30B interface, allowing PLA crystallization [22]. In semi-crystalline PLA, chain conformation and developed crystallinity are sensitive to surface interactions. It is possible, in the case of nanocomposites, that the high surface interaction between the polymer chains and the nanoclay surface tends to change the degree of crystallinity because of a heterogeneous nucleation effect. Two overlapping melting processes at $c a$. $153^{\circ} \mathrm{C}$ are shown in both PLA/B and PLA/C $30 \mathrm{~B}$, which may correspond to different crystals sizes. The shoulder almost disappears in nanocomposites with the lowest $M_{n}$, which may indicate that only one size of crystal remained. It is worth mentioning that similar $X_{c}$ was observed as the $M_{n}$ decreased to the lowest value in both blank PLA and nanocomposite. $M_{\mathrm{n}}$ has minimal effects on $\Delta H_{\mathrm{c}}$; 
however, $T_{\mathrm{c}}$ decreased $c a .15{ }^{\circ} \mathrm{C}$ and $c a .26^{\circ} \mathrm{C}$ in PLA/B and PLA/C30B, respectively. This indicates that longer PLA chains require higher kinetic energy to break down intermolecular bonds, while the free energy of crystallization of PLA remains. When nanoparticles are introduced into the organic polymer matrix, the polymorphic crystalline form would be induced, giving the nanocomposites many excellent properties, mainly including rapid crystallization [25]. The latter results can be supported by the results of Young et al. [26] in their research of PLA morphology and crystallization-they reported that as $T_{\mathrm{c}}$ decreases, the PLA spherulite radius also decreases from a value of $20 \mu \mathrm{m}$ at a $T_{\mathrm{c}}$ of $110^{\circ} \mathrm{C}$ to a spherulite radius of $160 \mu \mathrm{m}$ at a $T_{\mathrm{c}}$ of $140{ }^{\circ} \mathrm{C}$.

\subsubsection{X-ray Diffraction (XRD)}

The X-ray diffraction patterns of PLA/B and PLA/C30B at 0,176 , and $360 \mathrm{~h}$ of exposure to artificial weathering are shown in Figure 4. In both blank and nanocompounded PLA (Figure 4a), the diffractogram showed a broad intense peak around $16.5^{\circ}$ and a small peak located around $18.5^{\circ}$. These peaks are characteristic of PLA, which is in agreement with the results of dos Santos et al. [27] and Liu et al. [28]. Nanocompounded PLA (Figure $4 \mathrm{~b}$ ) showed a broad peak at $5.7^{\circ}$, which corresponds to C30B. The difference in intensity in each diffractogram is due to the increase in the crystallinity of PLA at different artificial weathering exposure times. As can be seen from both diffractograms, the intensity of PLA/B and PLA/C30B increases as the artificial weathering exposure time augments. These results are in good agreement with those obtained by DSC (Section 3.2.2.). Chain scission of PLA due to artificial weathering, together with $\mathrm{C} 30 \mathrm{~B}$ reinforcement favoring the formation of orderly polymer chains, exhibits the development of enhanced crystallinity, and therefore an increase of $X_{\mathrm{c}}(\%)$.

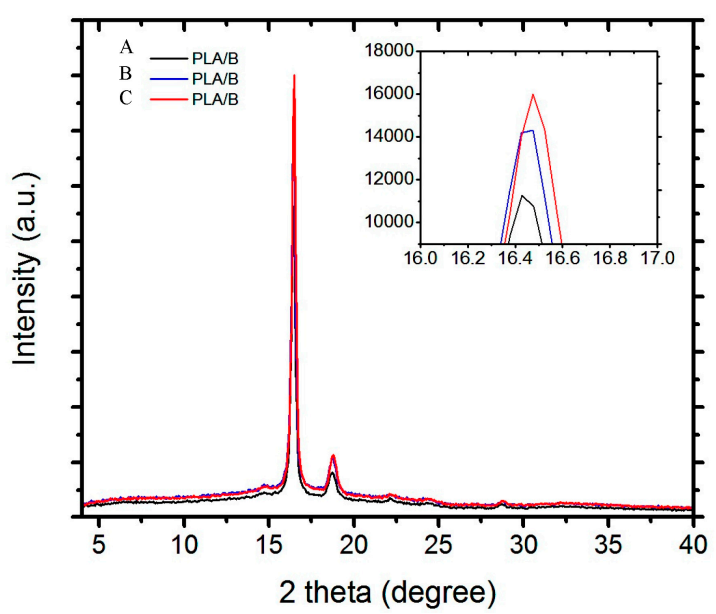

(a)

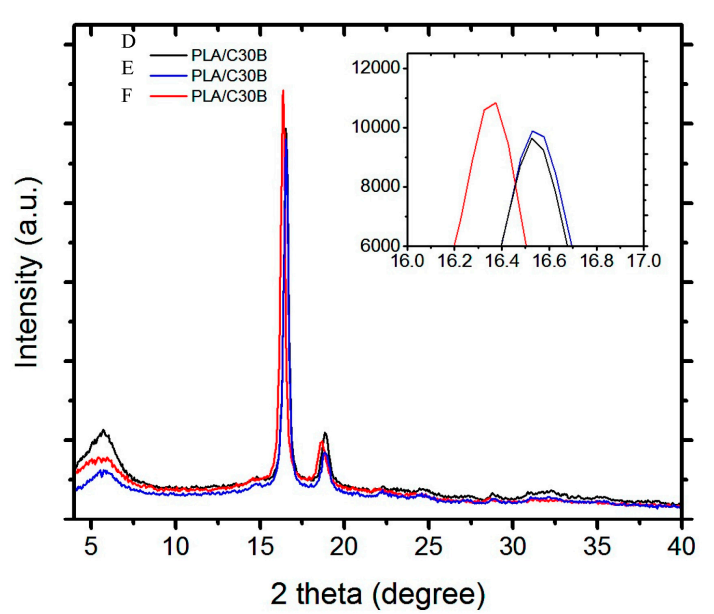

(b)

Figure 4. X-ray diffraction (XRD) diffractograms of (a) PLA/B $\left(M_{\mathrm{n}}\right.$ in $\mathrm{kg} \cdot \mathrm{mol}^{-1}$ of $\mathrm{A}=49.0, \mathrm{~B}=33.1$, and $\mathrm{C}=16.4)$; and (b) PLA/C30B $\left(M_{\mathrm{n}}\right.$ in $\mathrm{kg} \cdot \mathrm{mol}^{-1}$ of $\mathrm{D}=43.5, \mathrm{E}=31.9$, and $\left.\mathrm{F}=11.3\right)$.

Also, a small peak shift from $16.5^{\circ}$ to $16.35^{\circ}$ was observed in PLA/C $30 \mathrm{~B}$ at $360 \mathrm{~h}$ of exposure to artificial weathering. This may be due to a decrease of the size of the crystal, as previously discussed in Section 3.2.2. From DSC results, it could be observed that the $T_{\mathrm{m}}$ shoulder in PLA/C30B with the lowest $M_{\mathrm{n}}$ almost disappears, which may indicate that only one crystal size remained.

\subsubsection{Dynamic Thermo-Mechanical Analysis (DTMA)}

An essential element in biodegradable applications of polymers is the development of physical and mechanical properties without leaving aside the degradation rate of these polymers. The degradation rate is governed by different factors, such as the nature of the polymer, environmental conditions, and the $M_{\mathrm{W}}$. For instance, $M_{\mathrm{W}}$ has a direct correlation with the rate of degradation. Therefore, the design 
of biodegradable products with the best mechanical properties and lowest $M_{\mathrm{W}}$ is imperative in order to ensure their short-term degradation.

Figure 5 shows the $E^{\prime}$ and $\tan \delta$ of PLA blank and its nanocomposites as a function of temperature. The curve of both PLA/B and PLA/C30B demonstrates that PLA exhibits glassy, glass-transition, and rubbery behaviors. Also, the curves of PLA/B samples have a similar shape to PLA/C30B along the temperature range from 30 to $90^{\circ} \mathrm{C}$.

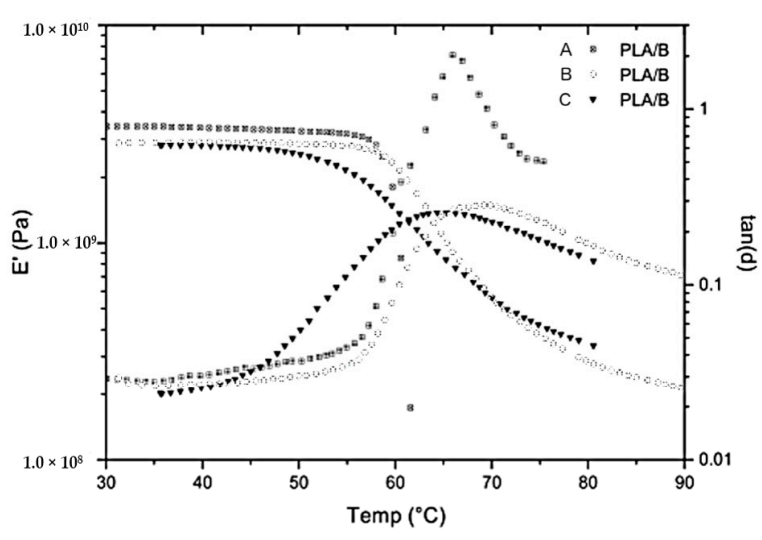

(a)

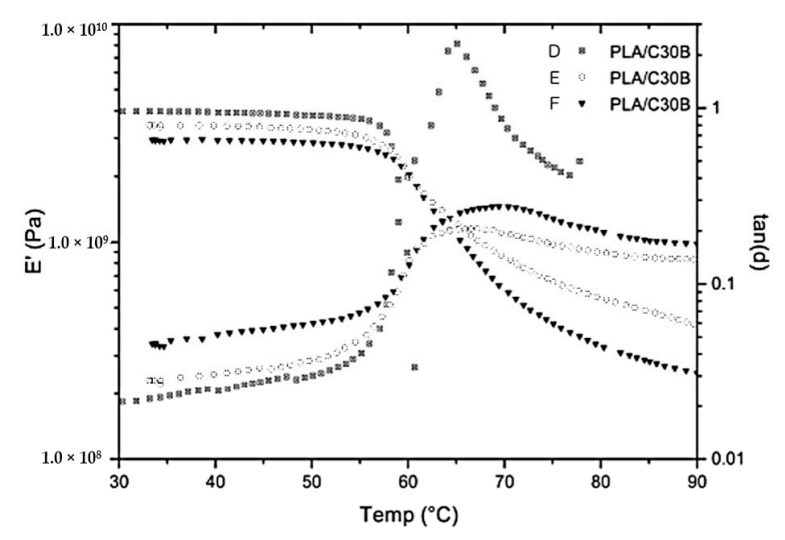

(b)

Figure 5. Results of Dynamic Thermo-Mechanical Analysis (DTMA): Storage modulus ( $\left.E^{\prime}\right)$ and $\tan \delta$ of (a) PLA/B $\left(M_{\mathrm{n}}\right.$ in $\mathrm{kg} \cdot \mathrm{mol}^{-1}$ of $\mathrm{A}=49.0, \mathrm{~B}=33.1$, and $\left.\mathrm{C}=16.4\right)$ and; (b) PLA/C30B $\left(M_{\mathrm{n}}\right.$ in $\mathrm{kg} \cdot \mathrm{mol}^{-1}$ of $\mathrm{D}=43.5, \mathrm{E}=31.9$, and $\mathrm{F}=11.3)$.

Table 4 gives a summary of $E^{\prime}$ and $T_{\mathrm{g}}$ of PLA/B and PLA/C30B, both with different $M_{\mathrm{n}}$ after artificial weathering.

Table 4. Mechanical properties of PLA blank and nanocomposites.

\begin{tabular}{ccc}
\hline Sample & $\boldsymbol{E}^{\prime}(\mathbf{G P a})$ & $\boldsymbol{T}_{\mathbf{g}}\left({ }^{\circ} \mathbf{C}\right)$ \\
\hline PLA/B $\left(M_{\mathrm{n}} 49.04 \mathrm{~kg} \cdot \mathrm{mol}^{-1}\right)$ & 3.43 & 65.95 \\
PLA/B $\left(M_{\mathrm{n}} 33.06 \mathrm{~kg} \cdot \mathrm{mol}^{-1}\right)$ & 2.89 & 69.88 \\
PLA/B $\left(M_{\mathrm{n}} 16.40 \mathrm{~kg} \cdot \mathrm{mol}^{-1}\right)$ & 2.82 & 65.27 \\
PLA/C30B $\left(M_{\mathrm{n}} 43.49 \mathrm{~kg} \cdot \mathrm{mol}^{-1}\right)$ & 3.97 & 58.28 \\
PLA/C30B $\left(M_{\mathrm{n}} 31.90 \mathrm{~kg} \cdot \mathrm{mol}^{-1}\right)$ & 3.43 & 66.51 \\
PLA/C30B $\left(M_{\mathrm{n}} 11.32 \mathrm{~kg} \cdot \mathrm{mol}^{-1}\right)$ & 2.94 & 69.43 \\
\hline
\end{tabular}

The bonds or forces that keep PLA atoms or chains together are responsible for the viscoelastic properties of PLA. Absorption of the elastic energy into the PLA structure is followed by its dissipation to the structural elements and chemical bonds from the main chain. $E^{\prime}$ was found to be $3.43 \mathrm{GPa}$ for blank and 3.97 GPa for nanocomposites, both with the highest $M_{\mathrm{n}}\left(49.04\right.$ and $43.49 \mathrm{~kg} \cdot \mathrm{mol}^{-1}$, respectively). The incorporation of C30B into PLA matrix caused an increment in $E^{\prime}$ value (increment of $13 \%$ ) on the highest $M_{n}$, indicating that the modulus of PLA improves in the presence of C30B. This may be due to the fact that clay nanolayers restrict the mobility of the surrounding matrix chains and limit the plastic deformation of PLA; thus, stronger interactions between PLA and nanolayers of C30B are obtained. Nanocomposite with a $M_{\mathrm{n}}$ of $31.90 \mathrm{~kg} \cdot \mathrm{mol}^{-1}$ had the same $E^{\prime}$ increment. However, nanocomposites with the lowest $M_{\mathrm{n}}\left(11.32 \mathrm{~kg} \cdot \mathrm{mol}^{-1}\right)$ showed a small improvement in $E^{\prime}$ with respect to its blank (increment of $5 \%$ ), but still had a better $E^{\prime}(2.95 \mathrm{GPa})$ than blank PLA ( $E^{\prime}=2.89 \mathrm{GPa}$ ) with an $M_{\mathrm{n}}$ of $33.06 \mathrm{~kg} \cdot \mathrm{mol}^{-1}$; this may be associated with the major effect of PLA/C30B interactions rather than $M_{n}$ decay. 
PLA has three main functional groups: ester, hydroxyl, and carboxyl groups. On the other hand, C30B organomodifier contains hydroxyl groups that interact with functional groups of PLA via hydrogen bonding, as shown in Figure 6 . As the $M_{n}$ was reduced, more carboxyl and hydroxyl groups of PLA formed during photo-oxidative chain scission, which means that there were more interaction sites between PLA and the C30B organomodifier, improving PLA crystallization.

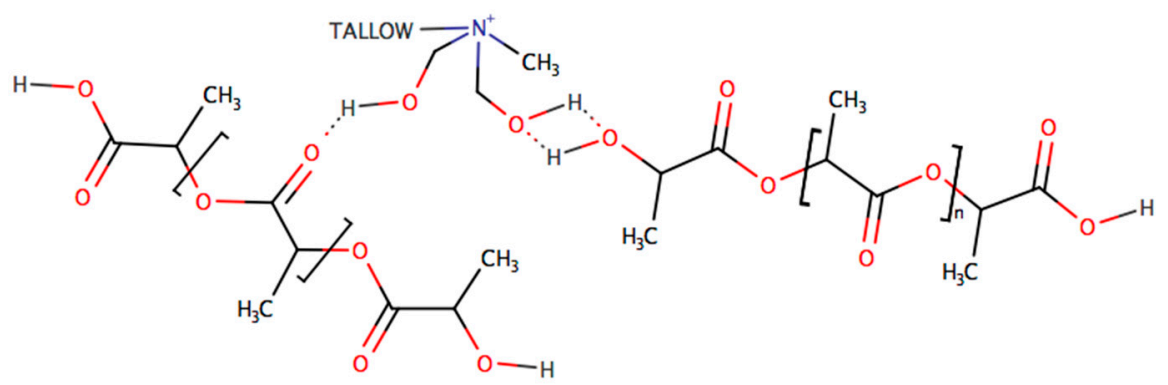

Figure 6. Suggested interactions between the C30B organomodifier and PLA.

The aforementioned suggests that filler interactions among functional groups of PLA and hydroxyl groups of the $\mathrm{C} 30 \mathrm{~B}$ organomodifier had a major effect on $E^{\prime}$ improvement rather than $M_{\mathrm{W}}$ decay. It could also be observed that $E^{\prime}$ of all PLA samples dropped after the $T_{\mathrm{g}}$. In semi-crystalline PLA, chain conformation and developed crystallinity are sensitive to surface interactions. That is why in nanocomposites, where a high surface interaction exists between PLA chains and C30B at the nanorange, nanocomposites tend to change their degree of crystallinity and rate of crystallization because of a heterogeneous nucleation effect. The $M_{\mathrm{W}}$ affects the degree to which internal strains form and recover. Because $E^{\prime}$ is related to the amount of stored energy during deformation, it provides an estimate of the degree of recovery of PLA. It has been found that the interactions of intercalated and/or exfoliated nanolayers may restrict the mobility of the PLA chains, which lead to an increase of $T_{\mathrm{g}}$ values, as observed by Yang et al. [29] $T_{\mathrm{g}}$ was established at the highest $\tan \delta$ value. Thus, DTMA allows us to study the variations in these parameters linked to macromolecular motions, not only the main one $\left(T_{\mathrm{g}}\right)$, but also the local movements not detected by DSC. However, $T_{\mathrm{g}}$ absolute value obtained by DSC and DTMA cannot be compared. PLA consisted of linear chain molecules having strong intramolecular bonds but weak intermolecular bonds. As the size of PLA chains was reduced $\left(M_{\mathrm{n}}\right.$ values lower than $\left.33.1 \mathrm{~kg} \cdot \mathrm{mol}^{-1}\right)$, mechanical damping was significantly improved, which was directly related to $T_{\mathrm{g}}$.

\subsubsection{Fourier Transform Infrared (FTIR) Spectroscopy}

Several studies have reported that the miscibility of polymer blends can be evaluated appropriately by monitoring the changes in IR vibrational frequency of carbonyl at $1760 \mathrm{~cm}^{-1}$ [30] and hydroxyl groups at $3760-3010 \mathrm{~cm}^{-1}$ [31]. As a result of an increase in $E^{\prime}$, and partial exfoliation of C30B into the PLA matrix to form PLA/C30B composites at nanorange, we suggest that intermolecular hydrogen bonds may exist in nanocomposites (see Figure 6). To further confirm this, ATR-FTIR analysis of PLA/B and PLA/C30B at the three artificial weathering exposure times $(0,176$, and $360 \mathrm{~h})$ was performed. Figure 7a depicts the FTIR spectra of PLA nanocompounded with $5 \mathrm{wt} \%$ load of C30B (PLA/C30B), and blank PLA (PLA/B) at $0 \mathrm{~h}$ of exposure to artificial weathering.

The PLA spectrum of both PLA/B and PLA/C30B at $0 \mathrm{~h}$ of exposure to artificial weathering shows $-\mathrm{CH}_{3}$ stretching at $2994.9-2942 \mathrm{~cm}^{-1}$. Also, $-\mathrm{C}=\mathrm{O}$ stretching at $1747.6 \mathrm{~cm}^{-1}$ and $-\mathrm{O}-\mathrm{C}=\mathrm{O}$ stretching at $1176.8-1079.4 \mathrm{~cm}^{-1}$ are displayed in both PLA/B and PLA/C30B, which are the main peaks of ester bonds.

Comparison between PLA/B and PLA/C30B at 176 and $360 \mathrm{~h}$ of exposure to artificial weathering were carried out in order to identify the source of the enhanced $E^{\prime}$ (described in Section 3.2.4.). The IR spectrum of PLA/B and PLA/C $30 \mathrm{~B}$ at $176 \mathrm{~h}$ is not shown here because they displayed a 
similar spectrum to PLA/B at 0 h. However, the ATR-FTIR spectrum of PLA/B and PLA/C30B at $360 \mathrm{~h}$ of exposure to artificial weathering is shown in Figure $7 \mathrm{~b}$. The presence of the stretching frequency of hydroxyl groups (3600-3050 $\mathrm{cm}^{-1}$ ) was found in PLA/C30B at $360 \mathrm{~h}$ of exposure to artificial weathering, which is one of the basic IR characteristics of the formation of hydrogen bonds. According to Orozco et al. [30], the broad band in the range of $3760-3010 \mathrm{~cm}^{-1}$ indicates hydrogen-bonded hydroxyl groups in starch. It seems that hydroxyl in C30B organomodifier gets involved in the formation of intermolecular hydrogen bonding with PLA matrix, as previously explained in Figure 6. However, since the amount of C30B was only $5 \mathrm{wt} \%$ in PLA/C $30 \mathrm{~B}$ blends, and also because only about one third of total mass corresponds to the amount of organomodifier, the $-\mathrm{OH}$ stretching of PLA vibrational frequency is very weak.

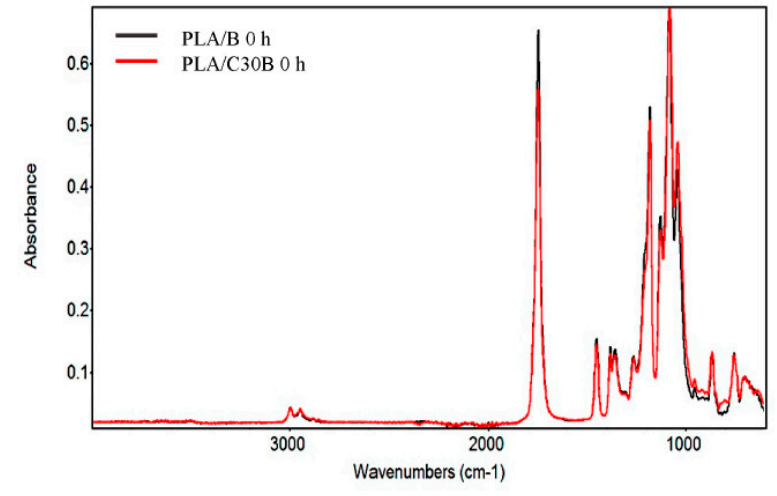

(a)

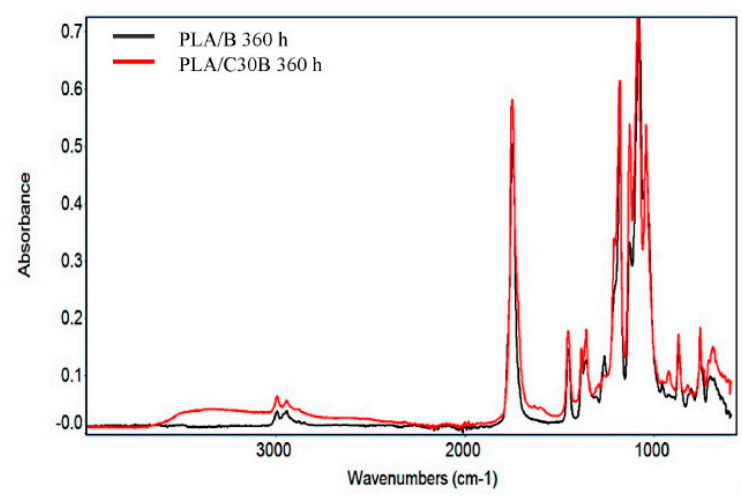

(b)

Figure 7. IR spectra of (a) PLA/B and PLA/C30B ( $0 \mathrm{~h}$ of exposure to artificial weathering) and; (b) PLA/B and PLA/C30B $\left(M_{\mathrm{n}}\right.$ in $\mathrm{kg} \cdot \mathrm{mol}^{-1}$ of $\mathrm{D}=43.5, \mathrm{E}=31.9$, and $\left.\mathrm{F}=11.3\right)$.

An enlargement of the carbonyl peak at $1745 \mathrm{~cm}^{-1}$ was also observed. In some studies [32], a semicrystaline polymer with a $-\mathrm{C}=\mathrm{O}$ of $1747 \mathrm{~cm}^{-1}$ has been blended with another semicrystalline polymer of Polyhydroxybutyrate (PHB) with a $-\mathrm{C}=\mathrm{O}$ of $1714 \mathrm{~cm}^{-1}$. The weak interaction between the carbonyl groups and hydrogen atoms of both matrices through hydrogen bonding leads to a miscible blend, which results in an overlaid $\mathrm{C}=\mathrm{O}$ peak in the FTIR spectra of PLA/C30B blend. The low vibrational frequency of $-\mathrm{C}=\mathrm{O}$ may be ascribed to the formation of intermolecular hydrogen bonds.

\section{Conclusions}

In this study, Cloisite30B dispersed at nanorange throughout the PLA matrix was used in order to investigate the thermo-mechanical properties of PLA nanocomposites with different $M_{\mathrm{W}}$.

The $M_{n}$ values of PLA blank and nanocomposites showed decay due to processing before exposure to artificial weathering. The $M_{\mathrm{n}}$ of irradiated PLA/B and PLA/C30B decreased notably in comparison with original PLA; this clearly showed a depolymerization of PLA by artificial weathering.

Thermal treatments of $\mathrm{C} 30 \mathrm{~B}$ were performed in order to study the thermal degradation of organomodifier during nanocomposite processing. The results showed that the weight loss during processing of the organomodifier was negligible. In addition, $\mathrm{C} 30 \mathrm{~B}$ alone was subjected to the same three artificial weathering exposure times $(0,176$, and $360 \mathrm{~h})$ as blank and nanocomposites without observing significant degradation of the organomodifier due to photodegradation. The content of organomodifier of $\mathrm{C} 30 \mathrm{~B}$ (amounting to about one third of the total mass) remains available to allow interactions with PLA.

The thermal stability of the PLA matrix was not improved by the presence of C30B in comparison with PLA/B in either of the samples with different $M_{\mathrm{W}}$. On the contrary, it could be observed that $T_{\mathrm{g}}$ obtained by DSC of PLA decreased as the $M_{n}$ decreased, which may be attributed without any doubt to chain scission during artificial weathering degradation. 
On the other hand, $T_{\mathrm{g}}$ obtained by DTMA analysis increased as $M_{\mathrm{n}}$ decreased due to the amount of stored energy during deformation that was related to $E^{\prime}$ improvement (increment of $13 \%$ ). It has been found that the interactions of exfoliated nanolayers may restrict the mobility of the PLA chains, which led to an increase of $E^{\prime}$ and $T_{\mathrm{g}}$ values. We suggest that filler/polymer interactions are still present between the functional groups of PLA and the hydroxyl groups of C30B organomodifier, even at the longest artificial weathering exposure time, which led to a major $\mathrm{E}^{\prime}$ improvement due to hydrogen bonding.

Acknowledgments: The authors wish to thank the National Council for Science and Technology of México (CONACYT) for the grant awarded to Wendy Margarita Chávez-Montes. We also wish to thank Victor Manuel Orozco Carmona and Daniel Lardizábal Gutiérrez for their invaluable collaboration during this project. The authors acknowledge the technical support of the Nanotechnology National Laboratory at CIMAV.

Author Contributions: Wendy Margarita Chávez-Montes is the Ph.D. student who performed all the experiments and the overall experimental work. Guillermo González-Sánchez in CIMAV made TGA and DSC analysis. Sergio Gabriel Flores-Gallardo made DTMA analysis.

Conflicts of Interest: The authors declare no conflict of interest.

$\begin{array}{ll}\text { Abbreviations } & \\ \text { ATR-FTIR } & \text { Attenuated Total Reflectance-Fourier Transform Infrared } \\ \text { C30B } & \text { Cloisite30B } \\ \text { DMTA } & \text { Dynamic Mechanical Thermal Analysis } \\ \text { DSC } & \text { Differential Scanning Calorimetry } \\ \text { GPC } & \text { Gel Permeation Chromatography } \\ \text { HPLC } & \text { High Performance Liquid Chromatography } \\ \text { MMT } & \text { Montmorillonite } \\ M_{\mathrm{W}} & \text { Molecular Weight } \\ M_{\mathrm{W}} \mathrm{D} & \text { Molecular Weight Distribution } \\ M_{\mathrm{W}} & \text { Weight Average Molecular Weight } \\ M_{\mathrm{n}} & \text { Number Average Molecular Weight } \\ \text { PLA } & \text { Poly-Lactide } \\ \text { PLA/B } & \text { Poly-Lactide blank } \\ \text { PLA/C30B } & \text { Poly-Lactide nanocomposite } \\ \text { TGA } & \text { Thermogravimetric Analysis } \\ \text { THF } & \text { Tetrahydrofuran } \\ T_{\mathrm{g}} & \text { Glass Transition Temperature } \\ T_{\mathrm{c}} & \text { Cold Crystallization Temperature } \\ T_{\mathrm{m}} & \text { Melting Temperature } \\ X_{\mathrm{c}} & \text { Degree of Crystallinity } \\ \text { XRD } & \text { X-ray Diffraction }\end{array}$

\section{References}

1. Pongtanayuta, K.; Thongpina, C.; Santawiteeb, O. The effect of rubber on morphology, thermal properties and mechanical properties of PLA/NR and PLA/ENR blends. Energy Proced. 2013, 34, 888-897. [CrossRef]

2. Woo, J.; Taik, Y.; Park, O. Thermal characteristics of organoclay and their effects upon the formation of polypropylene/organoclay nanocomposites. Polym. Bull. 2000, 45, 191-198.

3. McLauchlin, A.R.; Thomas, N.L. Preparation and thermal characterisation of poly(lactic acid) nanocomposites prepared from organoclays based on an amphoteric surfactant. Polym. Degrad. Stab. 2009, 94, 868-872. [CrossRef]

4. Kumar, M.; Mohanty, S.; Nayak, S.K.; Rahail, M. Effect of glycidyl methacrylate (GMA) on the thermal, mechanical and morphological property of biodegradable PLA/PBAT blends and its nanocomposites. Bioresour. Technol. 2010, 101, 8406-8415. [CrossRef] [PubMed] 
5. Raquez, J.M.; Habibi, Y.; Murariu, M.; Dubois, P. Polylactide (PLA)-based nanocomposites. Prog. Poly. Sci. 2013, 38, 1504-1542. [CrossRef]

6. Fukushima, K.; Murariu, M.; Camino, G.; Dubois, P. Effect of expanded graphite/layered-silicate clay on thermal, mechanical and fire retardant properties of poly(lactic acid). Polym. Degrad. Stab. 2010, 95, 1063-1076. [CrossRef]

7. Zenkiewicz, M.; Richert, J.; Rózanski, A. Effect of blow moulding ratio non barrier properties of polylactide nanocomposite films. Polym. Test. 2010, 29, 251-257. [CrossRef]

8. Picard, E.; Espuche, E.; Fulchiron, R. Effect of an organo-modified montmorillonite on PLA crystallization and gas barrier properties. Appl. Clay Sci. 2011, 53, 58-65. [CrossRef]

9. Bandera, D.; Meyer, V.R.; Prevost, D.; Zimmermann, T.; Boesel, L.F. Polylactide/montmorillonite hybrid latex as a barrier coating for paper applications. Polymers 2016, 8, 75. [CrossRef]

10. Petinakis, E.; Liu, X.; Yu, L.; Way, C.; Sangwan, P.; Dean, K.; Bateman, S.; Edward, G. Biodegradation and termal decomposition of poly(lactic acid)-based materials reinforced by hydrophilic fillers. Polym. Degrad. Stab. 2010, 95, 1704-1707. [CrossRef]

11. Manavietehrani, I.; Fathi, A.; Badr, H.; Daly, S.; Shirazi, A.N.; Dehghani, F. Biomedical applications of biodegradable polyesters. Polymers 2016, 8, 20. [CrossRef]

12. Cervantes-Uc, J.M.; Cauich-Rodríguez, J.V.; Vázquez-Torres, H.; Garfias-Mesías, L.F.; Paul, D.R. Thermal degradation of commercialy available organoclays studied by TGA-FTIR. Thermochem. Acta 2007, 457, 92-102. [CrossRef]

13. Khankrua, R.; Pivsa-Art, S.; Hiroyuki, H.; Suttiruengwong, S. Effect of chain extenders on thermal and mechanical properties of poly(lactic acid) at high processing temperatures: Potential application in PLA/Polyamide 6 blend. Polym. Degrad. Stab. 2014, 108, 232-240. [CrossRef]

14. Badía, J.D.; Santonja-Blasco, L.; Moriana, R.; Ribes-Greus, A. Thermal analysis applied to the characterization of degradation in soil of polylactide: II. On the thermal stability and thermal decomposition kinetics. Polym. Degrad. Stab. 2010, 95, 2192-2199. [CrossRef]

15. Chang-Hong, H.; Chau-Hui, W.; Chin-I, L.; Yu-Der, L. Synthesis and characterization of TPO-PLA copolymer and its behavior. Polymer 2008, 49, 3902-3910.

16. Nieddu, E.; Mazzucco, L.; Gentile, P.; Benko, T.; Balbo, V.; Mandrile, R.; Ciardelli, G. Preparation and biodegradation of clay composites of PLA. React. Func. Polym. 2009, 69, 371-379. [CrossRef]

17. Zaidi, L.; Kaci, M.; Bruzaud, S.; Bourmaud, A.; Grohens, Y. Effect of natural weather on the structure and properties of polylactide/Cloisite 30B nanocomposites. Polym. Degrad. Stab. 2010, 95, 1751-1758. [CrossRef]

18. Chávez-Montes, W.; González-Sánchez, G.; López-Martínez, E.; Lira-Gómez, P.; Ballinas-Casarrubias, L.; Flores-Gallardo, S. Effect of artificial weathering on PLA/nanocomposite molecular weight distribution. Polymers 2015, 7, 760-776. [CrossRef]

19. Stloukal, P.; Verney, V.; Commereuc, S.; Rychly, J.; Matisova-Rychlá, L.; Pis, V.; Koutny, M. Assessment of the interrelation between photooxidation and biodegradation of selected polyesters after artificial weathering. Chemosphere 2012, 88, 1214-1219. [CrossRef] [PubMed]

20. Solarski, S.; Ferreira, M.; Devaux, E. Ageing of polylactide and polylactide nanocomposite filaments. Polym. Degrad. Stab. 2008, 93, 707-713. [CrossRef]

21. Filippi, S.; Paci, M.; Polacco, G.; Dintcheva, N.T.; Magagnini, P. On the interlayer spacing collapse of Cloisite C30B organoclay. Polym. Degrad. Stab. 2011, 96, 823-832. [CrossRef]

22. Pandey, J.K.; Reddy, K.; Kumar, A.; Singh, R.P. An overview on the degradability of polymer nanocomposites. Polym. Degrad. Stab. 2005, 88, 234-250. [CrossRef]

23. Rasselet, D.; Ruellan, A.; Guinault, A.; Miquelard-Garnier, G.; Sollogoub, C.; Fayolle, B. Oxidative degradation of polylactide (PLA) and its effects on physical and mechanical properties. Eur. Polym. J. 2014, 50, 109-116. [CrossRef]

24. Novikov, V.N.; Rössler, E.A. Correlation between glass transition temperatura and molecular mass in non-polymeric and polymer glass formers. Polymer 2013, 54, 6987-6991. [CrossRef]

25. Sabu, T.; Kuruvilla, J.; Sant, K.M.; Koichi, G.; Meyyarappallil, S.S. Polymer Composites, 1st ed.; Wiley-VCH Velag GmbH \& Co. KGaA: Boschstr, Weinheim, Germany, 2013.

26. Young, J.; Okamoto, M.; Okamoto, H.; Nakano, M.; Usuki, A.; Matsuda, M. Morphology and crystallization kinetics in a mixture of low-molecular weight aliphatic amide and polylactide. Polymer 2006, 47, 1340-1347. 
27. Dos Santos, F.A.; Bruno Tavares, M.I. Development and characterization of hybrid materials based on biodegradable PLA matrix, microcrystalline cellulose and organophilic silica. Polimeros 2014, 24. [CrossRef]

28. Liu, C.; Chan, K.W.; Shen, J.; Wong, H.M.; Yeung, K.W.; Tjong, S.C. Melt-compounded polylactid acid composite hybrids with hydroxyapatite nanorods and silver nanoparticles: Biodegradation, antibacterial ability, bioactivity and cytotoxicity. RCS Adv. 2015, 5, 72288-72299.

29. Yang, S.-L.; Wu, Z.-H.; Yang, W.; Yang, M.-B. Thermal and mechanical properties of chemical crosslinked polylactide (PLA). Polym. Test. 2008, 27, 957-963. [CrossRef]

30. Orozco, V.; Brostow, W.; Chonkaew, W.; Lopez, B. Preparation and characterization of poly(lactic acid)-g-maleic anhydride+ starch blends. Macromol. Symp. 2009, 277, 69-80. [CrossRef]

31. Zhang, W.; Dehghani-Sanij, A.A.; Blachburn, R.S. IR Study on hydrogen bonding in epoxy resin-silica nanocomposites. Prog. Nat. Sci. 2008, 18, 801-805. [CrossRef]

32. Mohanty, S.; Nayak, S.K.; Kaith, B.S.; Kalia, S. Nanocomposites based on inorganic nanoparticles. In Polymer Nanocomposites Based on Inorganic and Organic Nanomaterials, 2nd ed.; Wiley: Hoboken, NJ, USA, 2015; pp. 259-341.

(C) 2016 by the authors; licensee MDPI, Basel, Switzerland. This article is an open access article distributed under the terms and conditions of the Creative Commons Attribution (CC-BY) license (http://creativecommons.org/licenses/by/4.0/). 